\title{
THE RECONSTRUCTION OF THE OLD BRIDGE IN MOSTAR
}

\author{
COLAK, I.
}

Abstract: The reconstruction of the Old Bridge is one of the most valuable historical projects undertaken under the auspices of the UNESCO in the past several decades. The location of today's Mostar was mentioned for the first time in 1452 as "duo castelli al ponte de Neretva". Many traces and artifacts dating from the Prehistoric and Roman periods were discovered in Mostar and its surroundings, which proves that the area around today's Mostar was inhabited from ancient times. A wooden bridge built in the mid-15th century (1452) existed in the place of today's Old Bridge prior to the arrival of Turks. Today's stone Old Bridge was designed and built by Mimar Hayrudin, who was a student of Sinan, the greatest Turkish builder. The Old Bridge was a source of inspiration for architectural, visual, musical and other works of art. The Old Bridge was completed in 1566. The span between the supports of the Old Bridge is $28.70 \mathrm{~m}$, while the thickness of the vault is $80 \mathrm{~cm}$. The width measures of the vault are from 392 to $397 \mathrm{~cm}$. The arch was built from local stone called Tenelija. Construction of Halebija and Tara, the towers on either side of the Old Bridge, started in medieval times, long before the bridge was built. The towers were completed about a hundred years after completion of the bridge. The reconstruction of the towers was done together with the reconstruction of the Old Bridge. In this paper will be presented part about the archeological investigation, and then parts about the centering, design of the Old Bridge, used materials and details of reconstruction.

Key words: the reconstruction, Old Bridge, the arch, design, the centering
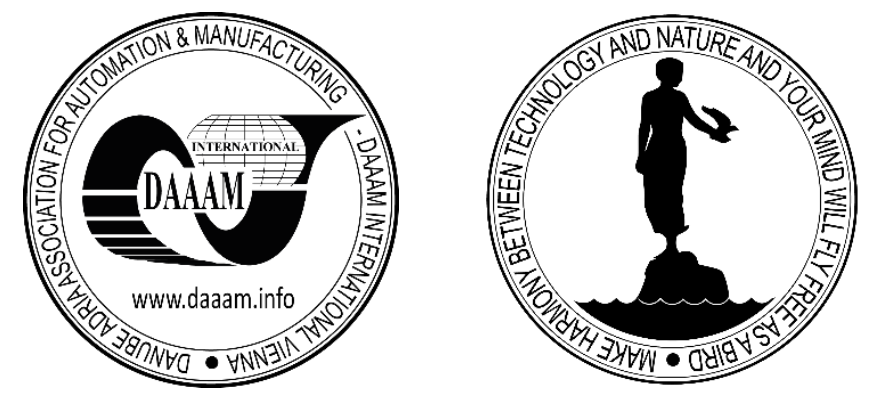

Authors' data: Univ. Prof. Ph. D. Dipl. Ing. Colak, I[vo]*,*Faculty of Civil Engineering University of Mostar, Matice hrvatske bb, Mostar, Bosnia \& Herzegovina, ivo.colak@gfmo.ba

This Publication has to be referred as: Colak, I[vo] (2016). The Reconstruction of the Old Bridge in Mostar, Chapter 14 in DAAAM International Scientific Book 2016, pp.151-162, B. Katalinic (Ed.), Published by DAAAM International, ISBN 978-3902734-09-9, ISSN 1726-9687, Vienna, Austria

DOI: $10.2507 /$ daaam.scibook.2016.14 


\section{Introduction}

The project of the reconstruction of the Old Bridge is one of the biggest and most valuable historical projects undertaken under the auspices of the UNESCO in the past several decades. The Old Bridge was a source of inspiration for architectural, visual, musical and other works of art.

The location of today's Mostar was mentioned for the first time in Dubrovnik archives in 1452 as "duo castelli al ponte de Neretva". That oldest written document witnessing the existence of medieval Mostar was the work of herzeg Stjepan Kosaca, a Herzegovinian nobleman. It was after him that Herzegovina was later named. Many traces and artifacts dating from the Prehistoric and Roman periods were discovered in Mostar and its surroundings, which proves that the area around today's Mostar was inhabited from ancient times. The city of Mostar was founded in the mid-15th century and built by Radoslav Gost, who was then in the service of herzeg Stjepan Kosaca. The available data suggest that the city was founded around 1440. Following the Ottoman invasion, Mostar came under the Turkish rule in 1468. The city was first mentioned in Turkish documents in 1477. A wooden bridge built in the mid-15th century existed in the place of today's Old Bridge prior to the arrival of Turks. Turkish Sultan Suleiman the Magnificent ordered the construction of a new stone bridge instead of the wooden one. The bridge was built by Mimar Hayrudin, who was a student of Sinan. Sinan was the greatest Turkish architect.

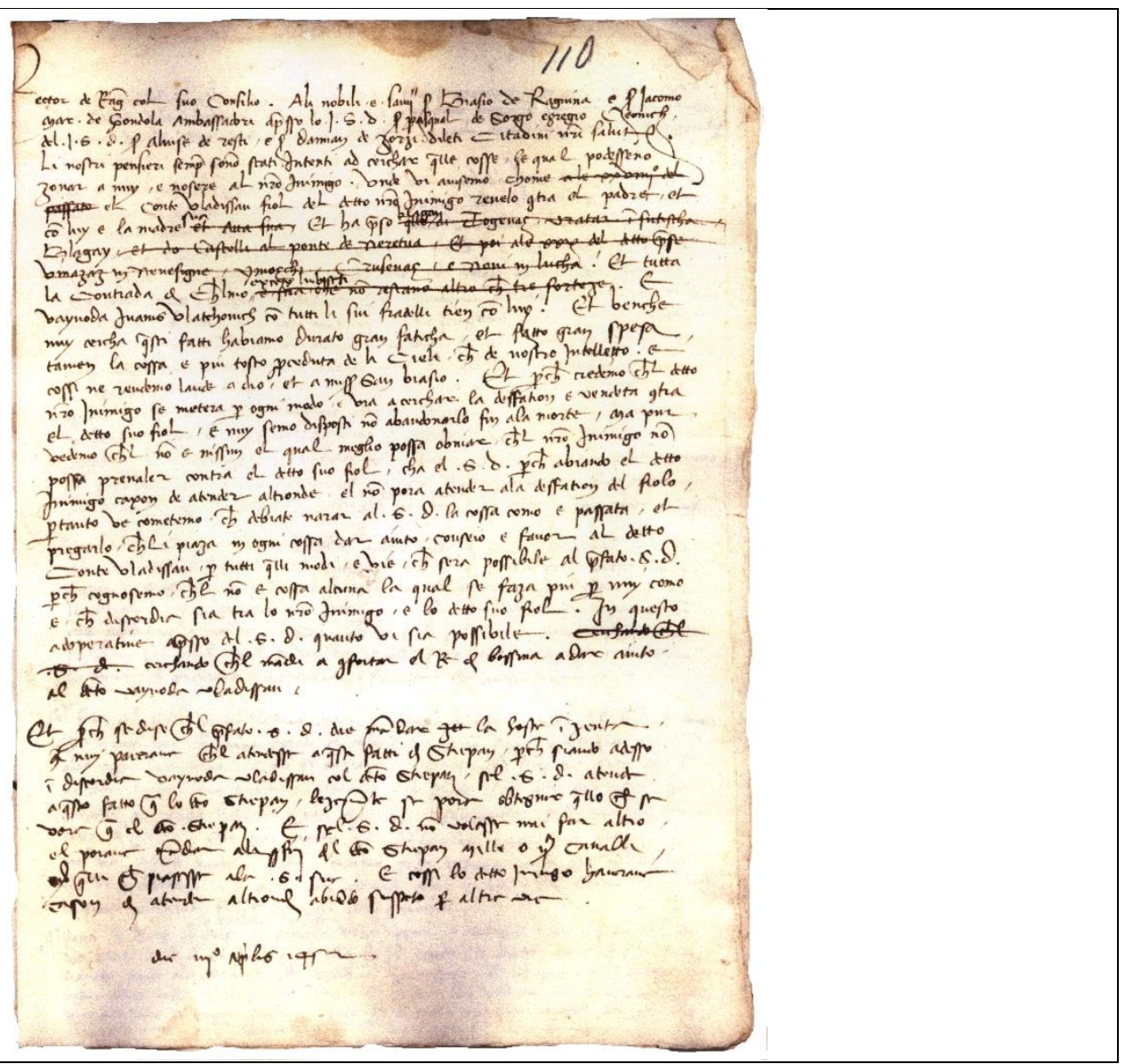

Fig. 1. The oldest written document (1452) witnessing the existence of medieval Mostar and it was the work of herzeg Stjepan Kosaca 


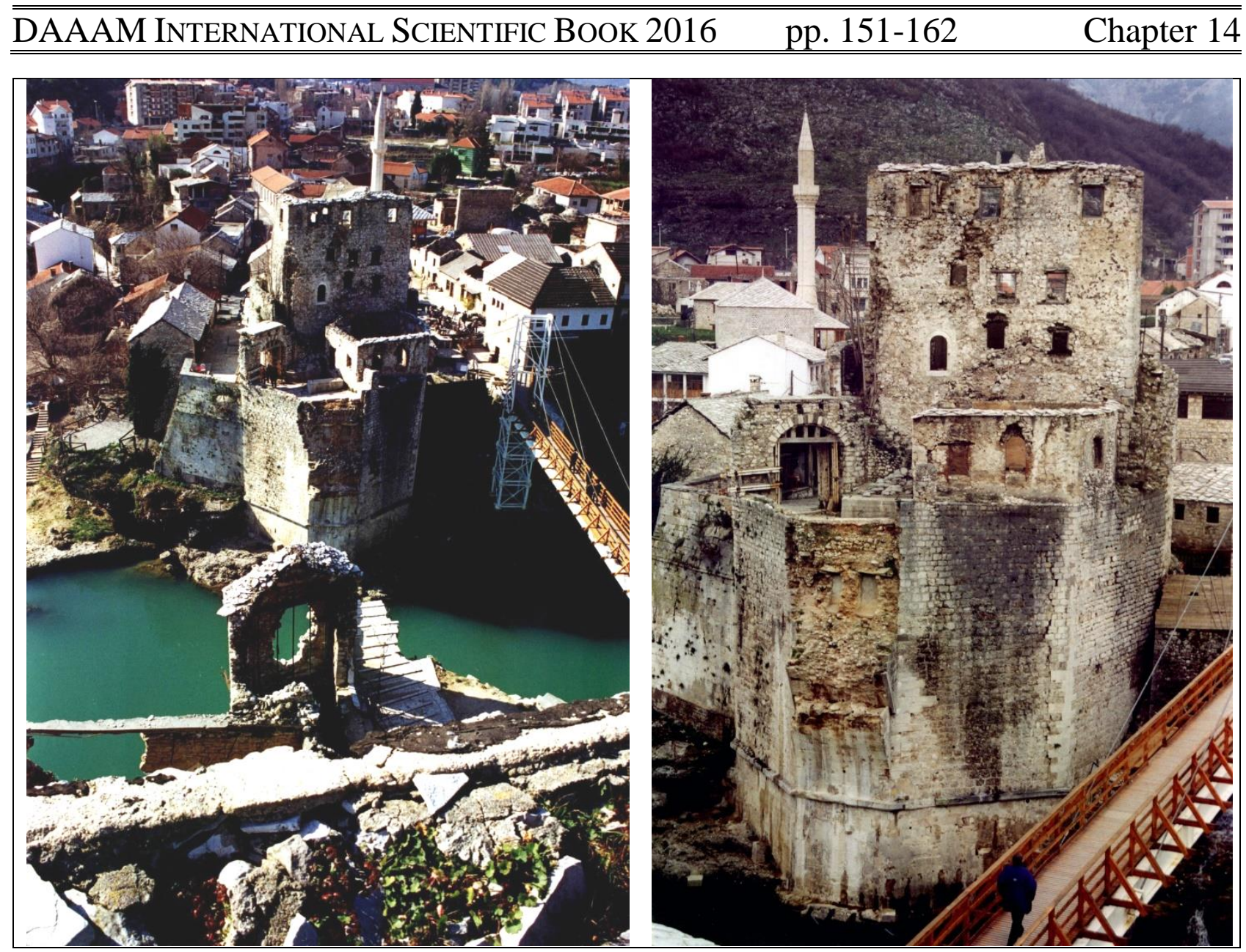

Fig. 2. The site of excavated walls beneath the Tara tower on the left riverbank and Halebija tower on the right riverbank (before the beginning of reconstruction)

Local citizens from Herzegovina and stonecutters and masons from Dalmatia participated in the bridge's construction. The Old Bridge was completed in 1566 . The span between the supports of the Old Bridge is $28.70 \mathrm{~m}$, while the thickness of the vault is $80 \mathrm{~cm}$. The width measures of the vault are from 392 to $397 \mathrm{~cm}$. The arch was built from local stone called tenelija of which there was an abundance, in the immediate area. Construction of Halebija and Tara, the towers on either side of the Old Bridge, started in medieval times, long before the bridge was built. The towers were completed about a hundred years after completion of the bridge. For centuries, the towers served as fortifications on the both banks of the Neretva river. The reconstruction of the towers was done together with the reconstruction of the Old Bridge. The first major conservation works on the Old Bridge were performed after the World War II and they lasted from 6 March to 19 July 1952. During the restoration works lasting from 1954 to 1957 the bridge's foundations and river banks were reinforced and consolidated, while the supports were restored using the injection method. The most important restoration work was done in 1963 when the vault was injected and damaged blocks were changed. (4) The archaeological research was done in 1982. During that same year, the photogrammetric survey of the bridge was performed, which enabled today's facsimile reconstruction of the Old Bridge. 


\section{Historical and Archaeological Research}

The archaeological research beneath the towers on both sides of the Old Bridge was done in two phases: the first one lasted from 1 January to 28 February 2002, and the second one from 14 November 2002 to 1 March 2003. The research was performed by the company "OMEGA Engineering" from Dubrovnik and led by Prof. Zeljko Pekovic PhD, Ante Milosevic PhD, and Nela Kovacevic (5). In the first archive documents that were found, the right bank of today's Mostar is mentioned as Cimski grad, with no mention of the bridge.

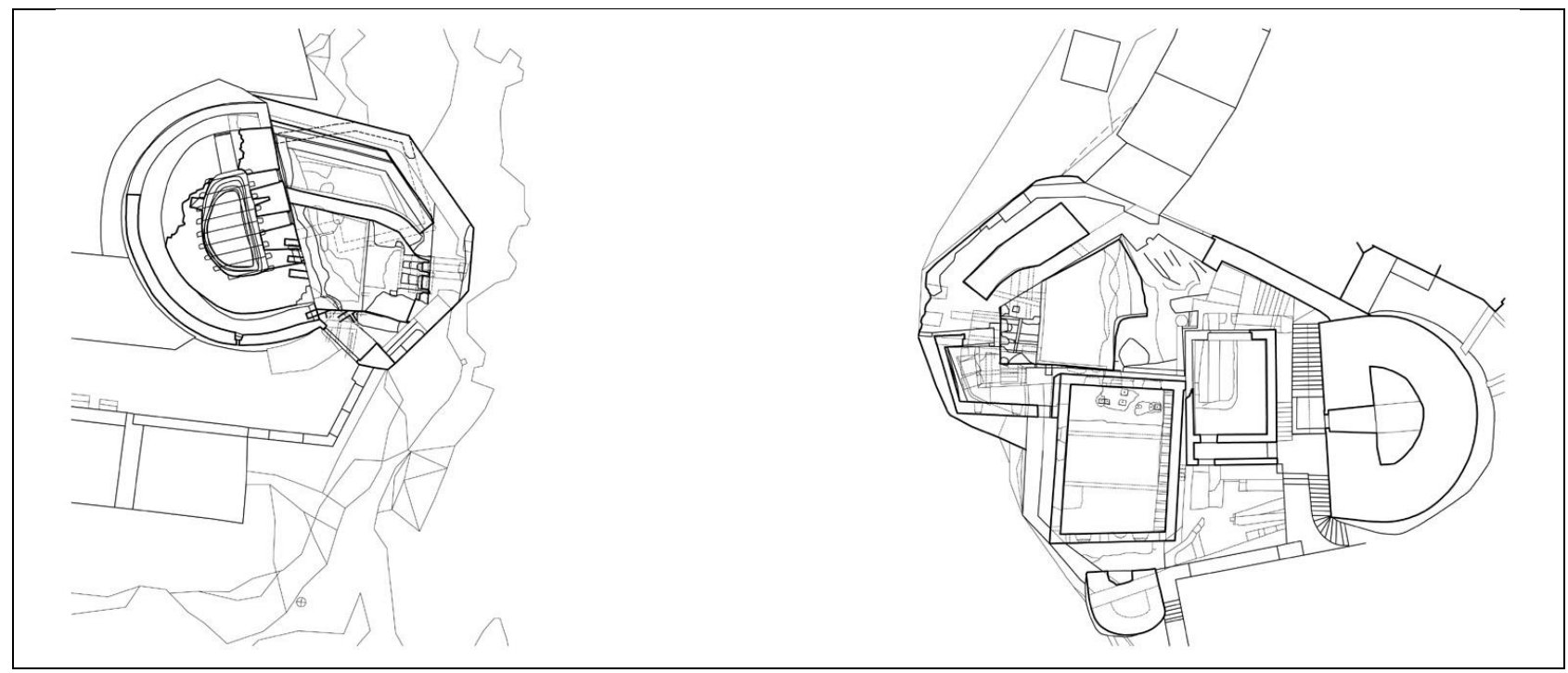

Fig. 3. Marks of excavated walls before the reconstruction

The wooden bridge was built in the mid-15th century. During the archaeological research the remnants of the previous wooden bridge were discovered and its foundations were found to be at the exact location of the future stone bridge. This is one of the most important recent archaeological findings. The results of the research were confirmed at the third UNESCO's session of experts in January 2003.

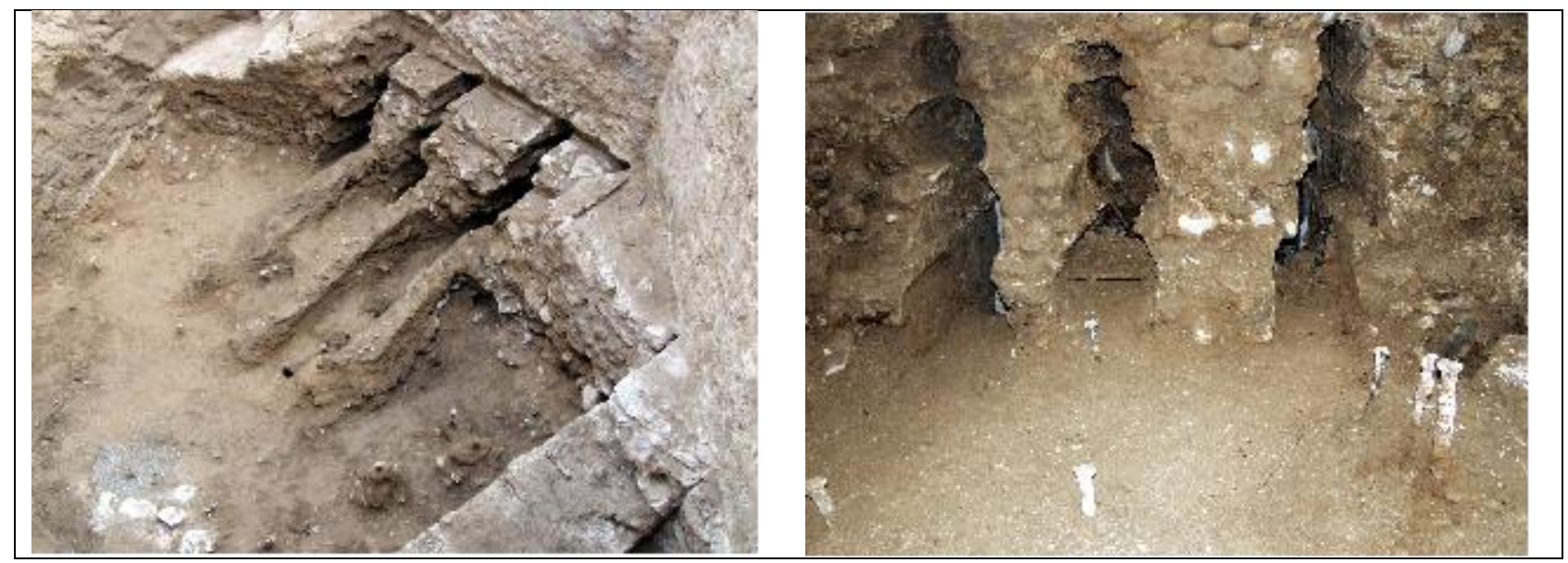

Fig. 4. Remnants of the foundations of the wooden mediaeval bridge with holes for the wooden consoles (marked steel wedges for connecting consoles are visible) 


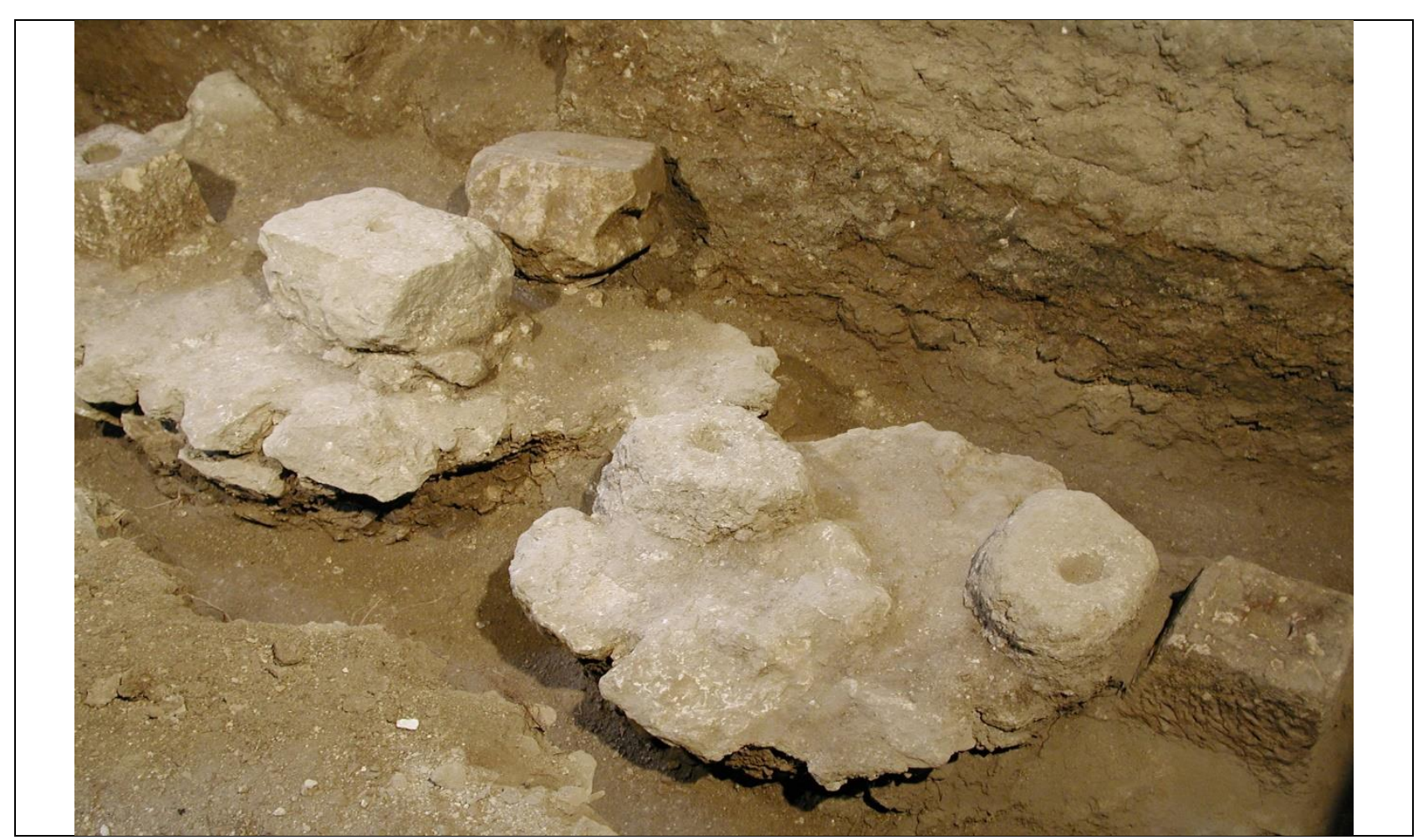

Fig. 5. Stone foundations of one path which led to the medieval wooden bridge (they were found underground and they contain openings for placement of the wooden consoles)

On the basis of the research performed and of the analysis of the archive documents the development of the site can be divided into several phases. There were towers on the both banks of the Neretva river in 1444, and in the mid-15th century the fortifications were connected by the wooden bridge. In the period between 1452 and 1566, the Halebija tower was reinforced by a wall and heightened with a wooden merlon. The Tara tower was also heightened in the same period.

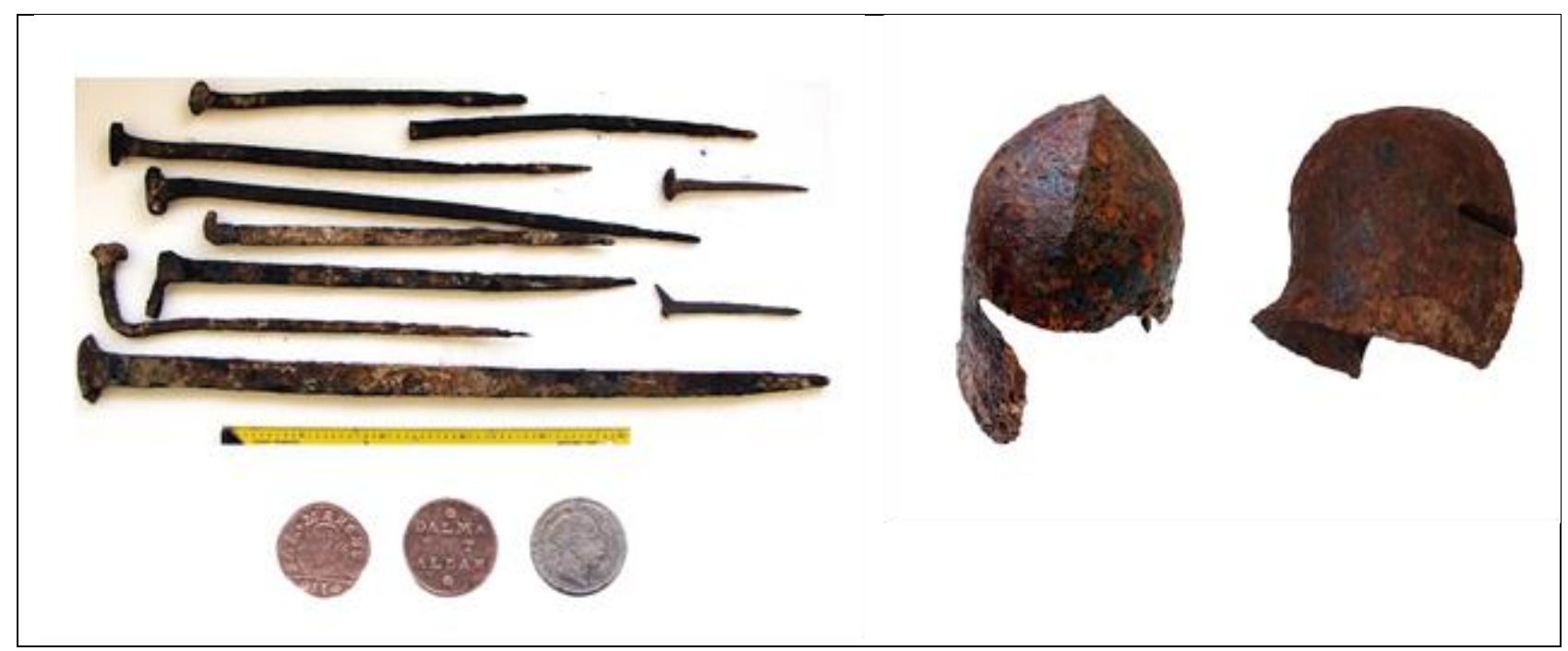

Fig. 6. Various sizes of steel wedges, Venetian coins (the bottom of the picture) and remnants of medieval helmets (right side) discovered on the site 


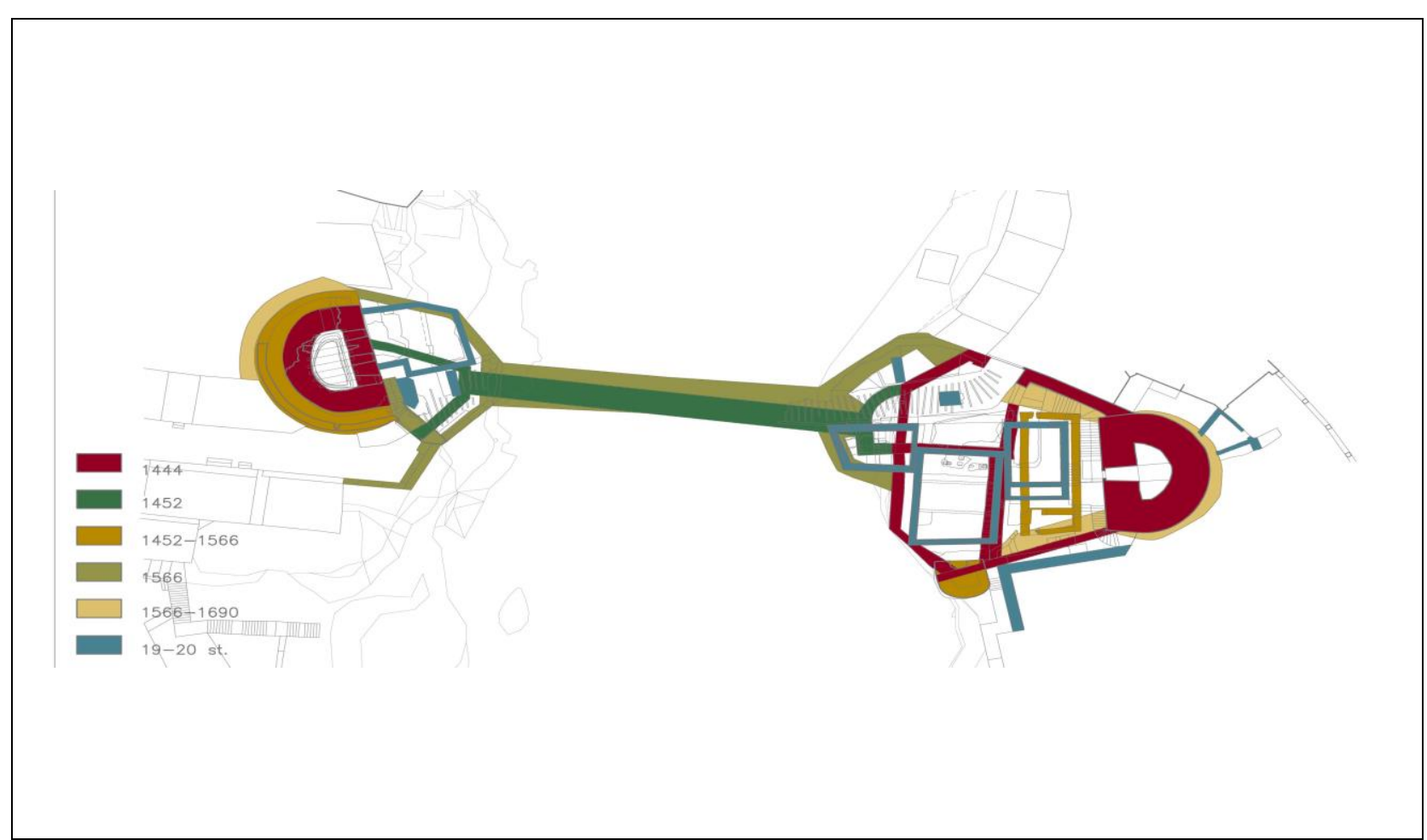

Fig. 7. Development of the locality of the towers and Old Bridge from 1444 to the 20th Century

The construction of the stone bridge was completed in 1566. From 1566 to 1690 the side walls were strengthened and both towers were heightened again with the adding of the new merlons. Between 1690 and 1878 some small changes were made at the facades with no new building works, and in 1715 the lower storeys of the Halebija tower were transferred into a prison. A fishmonger's, a shop, and a new building were added at the end of 19th and the beginning of the 20th centuries (lit. (6)).

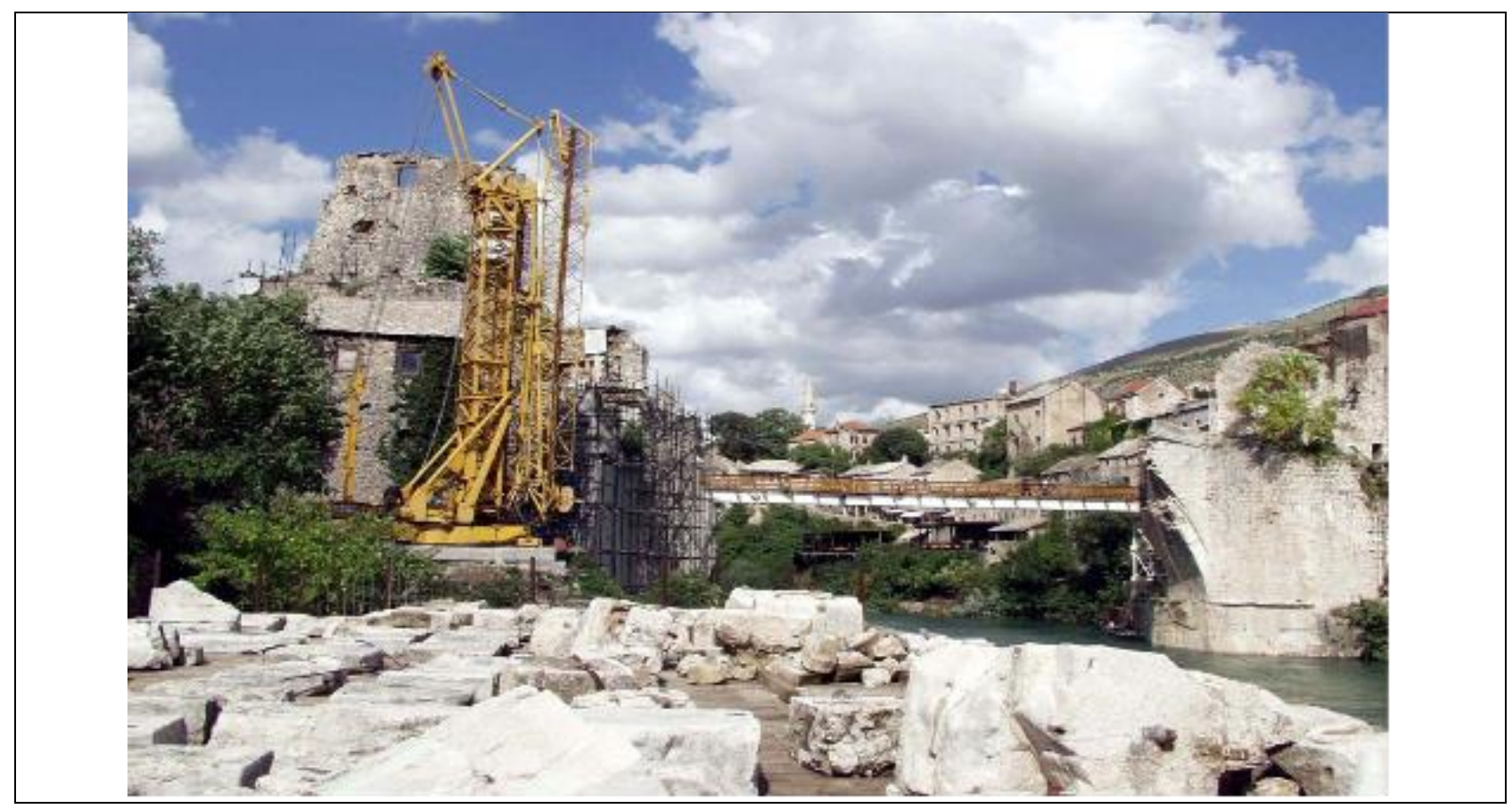

Fig. 8. The start of reconstruction of the Old Bridge, mounting of the first crane and scattered stone blocks on the platform by the river 


\section{The project of the reconstruction of the Old Bridge}

The first negotiations between the Mostar's city authorities and the representatives of the World Bank started in 1997 with a view to securing funds for the reconstruction of the Old Bridge and a part of the Old Town. The Project Loan Agreement was signed with the World Bank, which had its Pilot Coordination Unit in Mostar (lit. (1)). Also, UNESCO was included in the project in an advisory and consulting role in the course of the preparation of the project documentation and reconstruction works. The international tender for the reconstruction works on the Old Bridge was won by the Turkish company "ER-BU" from Ankara, while the role of the supervisor was assumed by the Croatian company "OMEGA Engineering" from Dubrovnik.

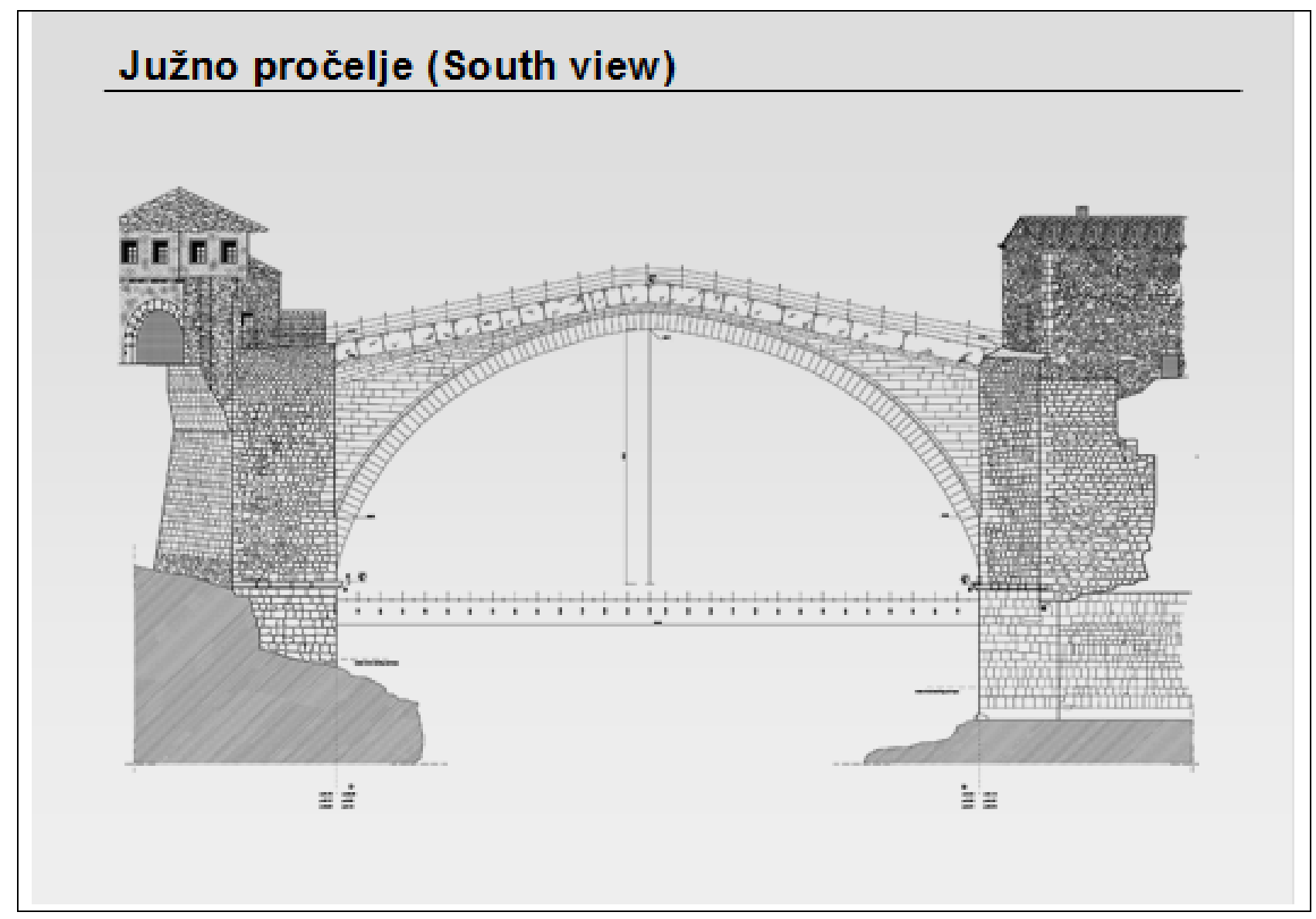

Fig. 9. Southern frontispiece of the Old Bridge

The preliminary project for the reconstruction of the Old Bridge was prepared by the Italian company "General Engineering" from Florence. The project, however, did not contain the data related to the real condition of either the Bridge's foundation or its statics. The complete excavation needed to be done so as to gain insight into the real condition of the foundation base. For example, there were experts who claimed that the Bridge's foundations were at the very bottom of the span, or that the towers were the constructive elements of the Bridge, which proved to be completely wrong assumptions. 
Fig. 10. The cross section before the beginning of reconstruction (the bold lines depict the current state, whereas the thin lines show the contours of what was to be done)

This part of the completion of the main project of the reconstruction of the Old Bridge as well as the finding of adequate solutions during the reconstruction works (not contained in the project) were mostly done by Prof. Blaz Gotovac PhD from the Faculty of Architecture and Civil Engineering in Split, who is also a member of the supervising company "OMEGA Engineering".

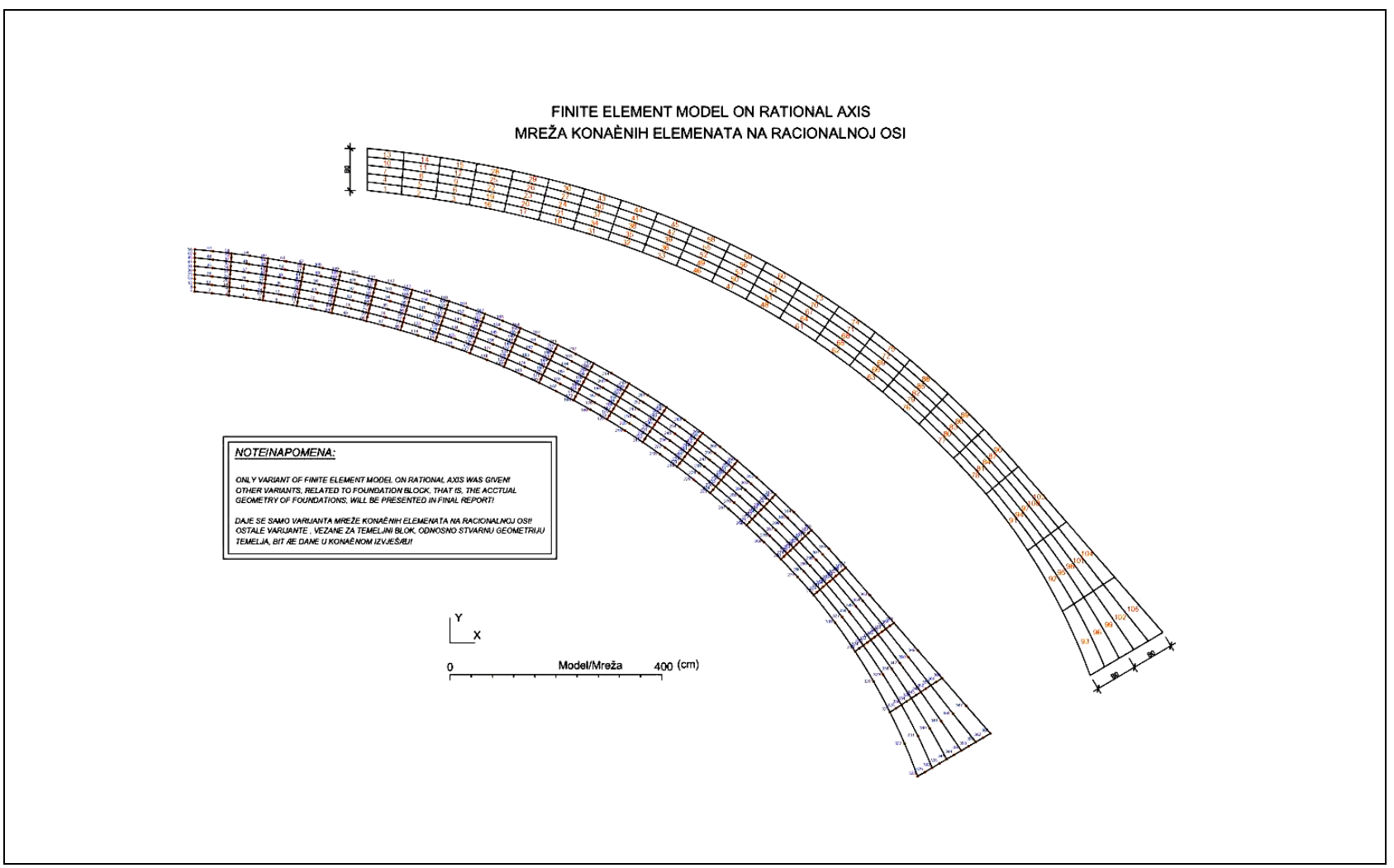

Fig. 11. The grid of finite elements on the rational axis (the picture shows the grid for one half or the arch and the model was made using SIGMA software package) 
Even before the archaeological excavations beneath the bridge's foundation started professor Gotovac assumed that the bases of the arch were significantly elevated, which artificially decreased the span of the bridge, while the lower parts of the arch served only as a "mask". Prof. Gotovac pointed out "... that lateral walls strengthen the bridge's arch, but they can be relatively moved in relation to the quay wall. Also, the middle third of the height from the beginning of the lower cornice to the beginning of the openings forms a part of the base of the arch which forms a monolithic connection to the quay bearing structure via big stone blocks. In that height range and over the whole arch, including the reinforcement under the openings, the arch is elastically fitted into the quay bearing structure. This is where Hayrudin performed an original move. He mortised a seven-centimeter-deep joint in the blocks belonging to both the lateral and quay walls thereby visually separating very important monolithic stone blocks and also misleading generations of builders for more than four centuries. The lower third of the arch's joint to the oblique quay wall from the beginning of the lower cornice to the base cornice was dilated with the lime mortar joint, which enabled the relative shift between the arch and oblique quay wall..." (lit. (3)). Prof. Gotovac gained the complete insight into the statics system after the mentioned lower rows of the arch were disassembled.

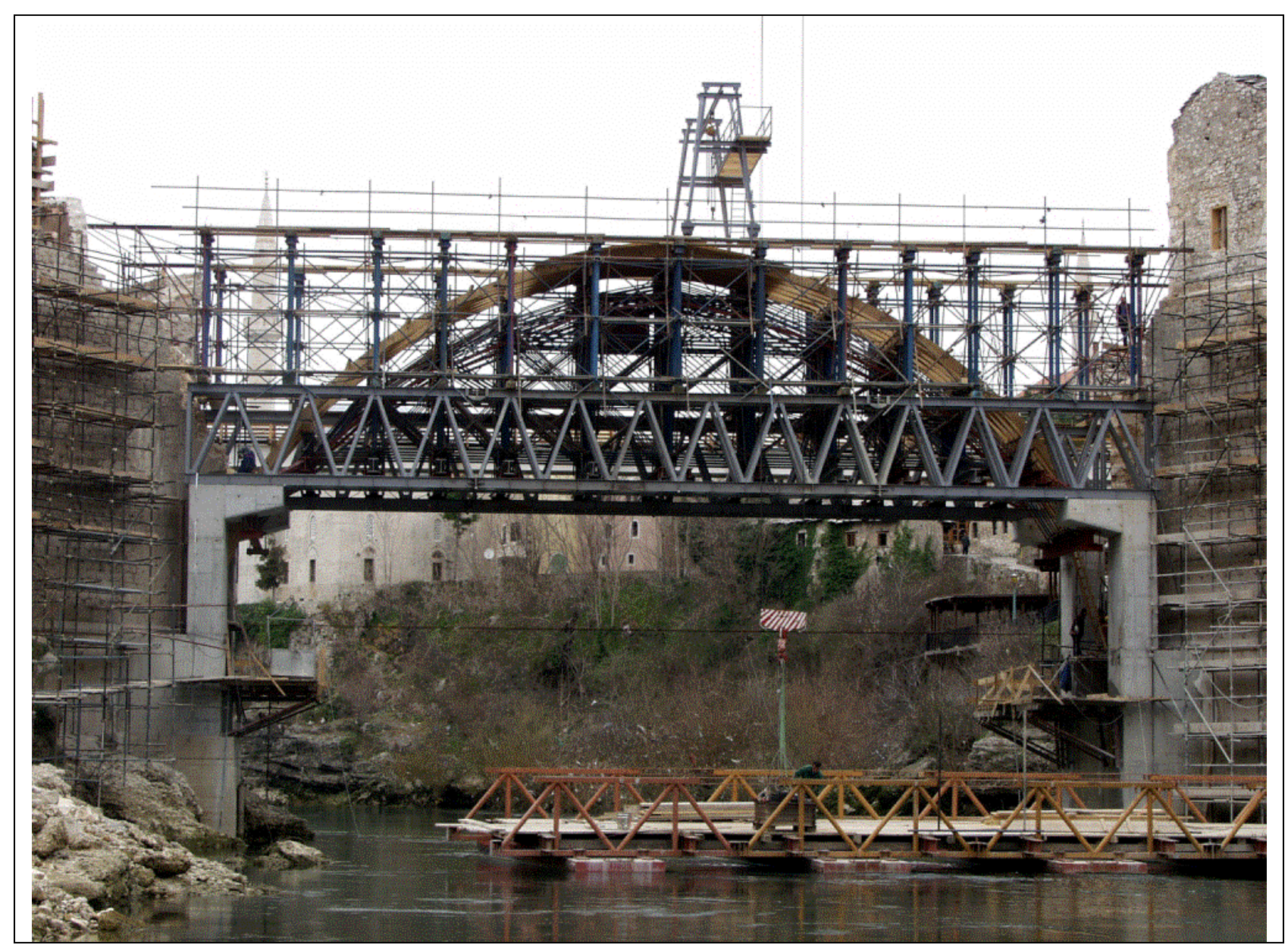

Fig. 12. Arch scaffolding on the concrete foundations with the pontoon bridge over the Neretva river 
The Old Bridge was not symmetrical and there were significant differences in its dimensions on its northern and southern sides, as well as the western and eastern ones. It can be said that the Old Bridge was distorted and twisted taking into account the mathematical differences in dimensions not visible with the naked eye.

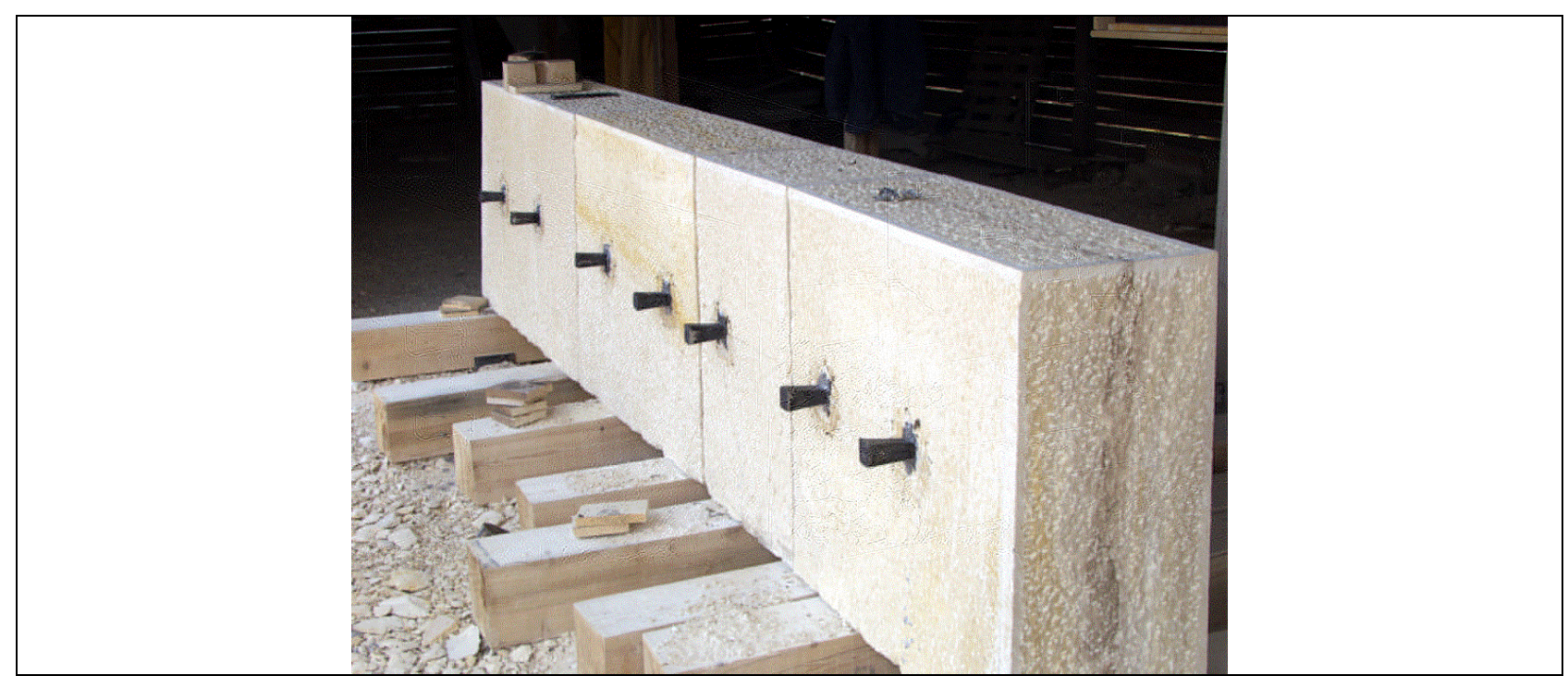

Fig. 13. A row of four stone blocks prepared for mounting

Those inaccuracies presented a problem because every irregularity had to be calculated with millimetre precision in the reconstruction project. The revision of the project of the reconstruction of the Old Bridge was done by the Faculty of Civil Engineering of the University of Mostar, while the assistant-professor Mladen Glibic $\mathrm{PhD}$ served as the official reviewer. One of the most important segments of the reconstruction was to select the adequate scaffolding for the heavy stone structure. The solution for the scaffolding was not proposed within the project of the reconstruction. The choice fell on the heavy scaffolding, which met all the conceptual requirements of the project, as opposed to the light arch scaffolding that is often used in building design and construction.

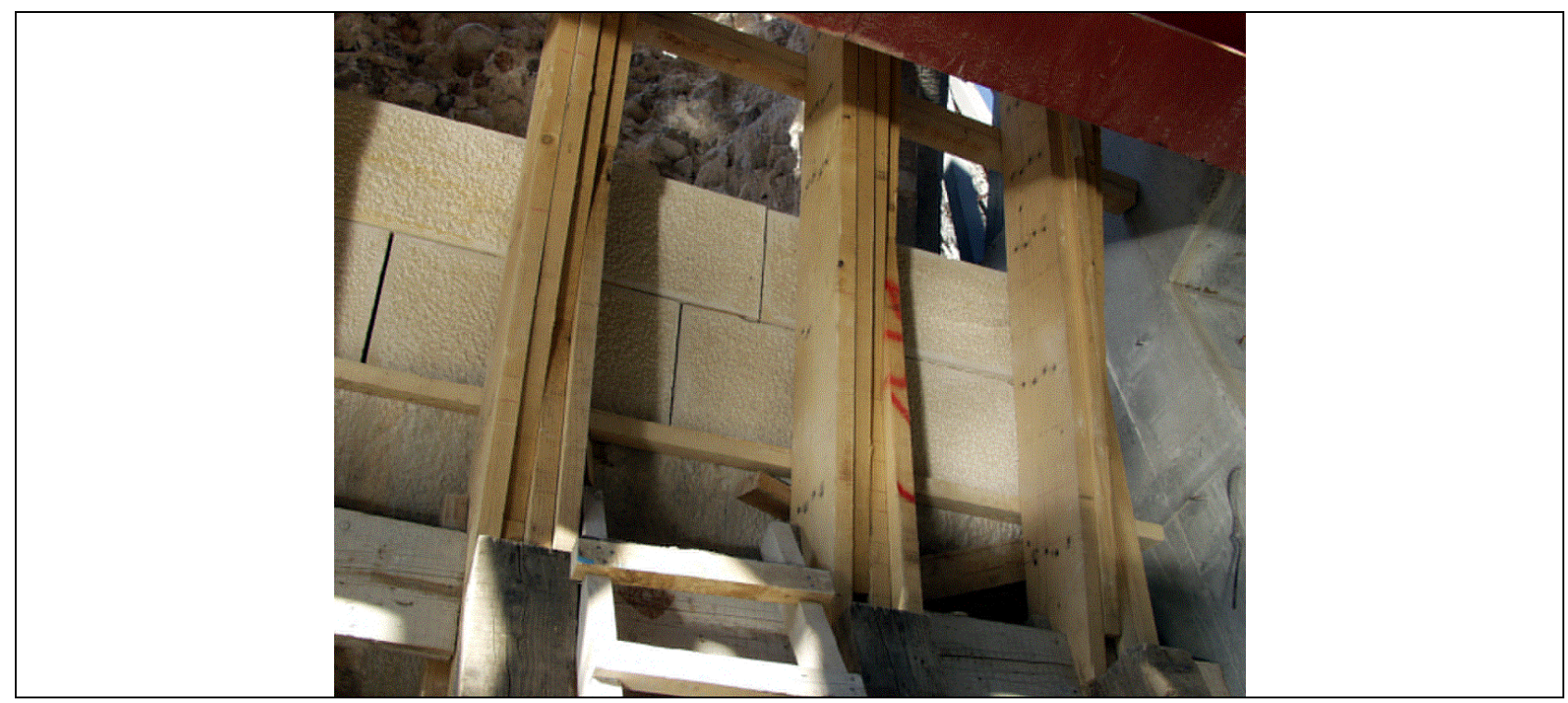

Fig. 14. The first rows of stone arch 
After the scaffolding was mounted, the endings of girders were prestressed into the pillars made of reinforced concrete. Thereby the trusses from the static beam structure were transformed into mutually prestressed trusses. The steel beam structure was placed at the both ends of the scaffolding to serve as the base for mounting the portal crane for placing the stone blocks in their desired positions. After the scaffolding was removed the shift was smaller than one millimetre, which fully justified the use of the steel scaffolding and proposed building concept.

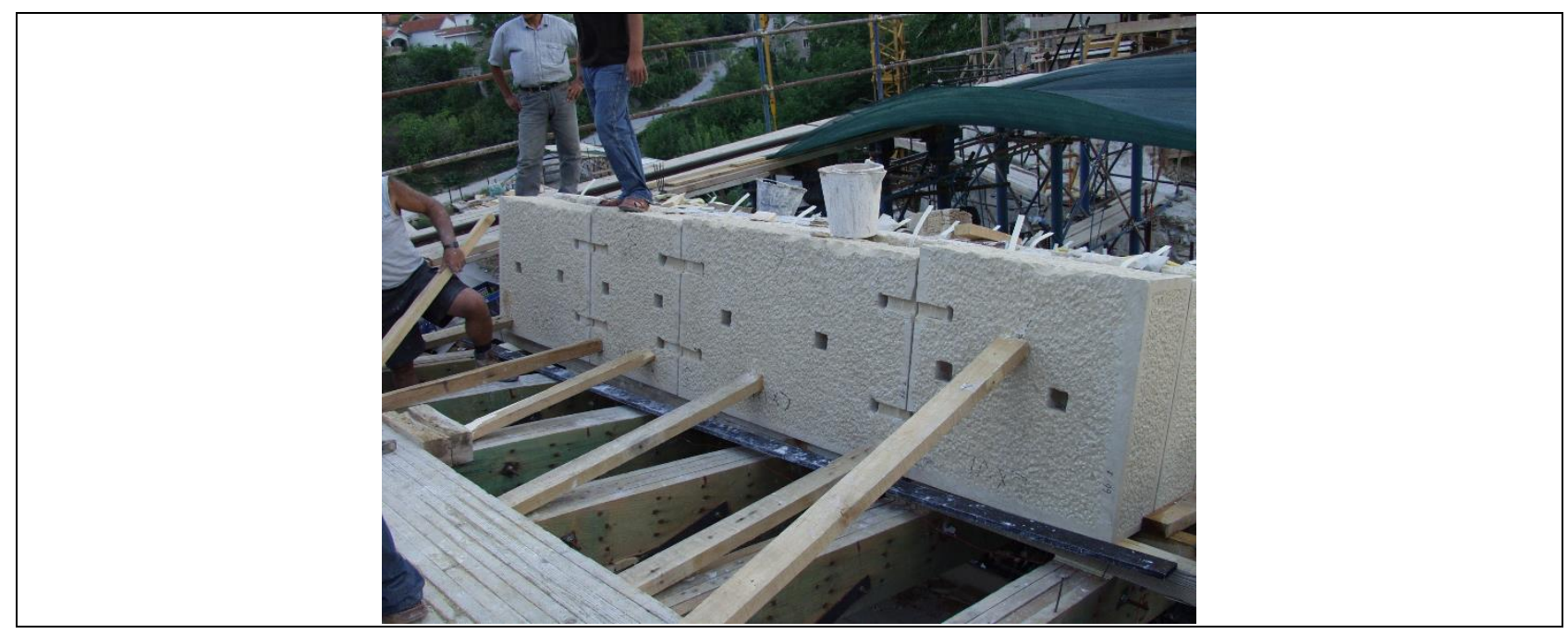

Fig. 15. The last rows of stone arch

The primary role in the project of the reconstruction belonged to the arch of the Old Bridge. In the 16th Century already the arch was "reinforced" with 30 tons of lead poured with dowels and cramps into the bridge's arch. The lead accounted for $10 \%$ of the total 300-ton mass of the arch. All stone blocks were connected with cramps, while the rows were longitudinally connected with 5 to 7 dowels each. Molten lead heated to the fixed temperature 390 degrees Celsius was poured into the space around dowels through channels made in stones. A very important joining part of the arch was the lime mortar that contained no artificial additives. The mortar between the arch's stone blocks is six millimetres thick. This whole procedure, from the defining of the project to the completion of the arch of the Old Bridge was delicate, unique and incomparable to any other project or construction.

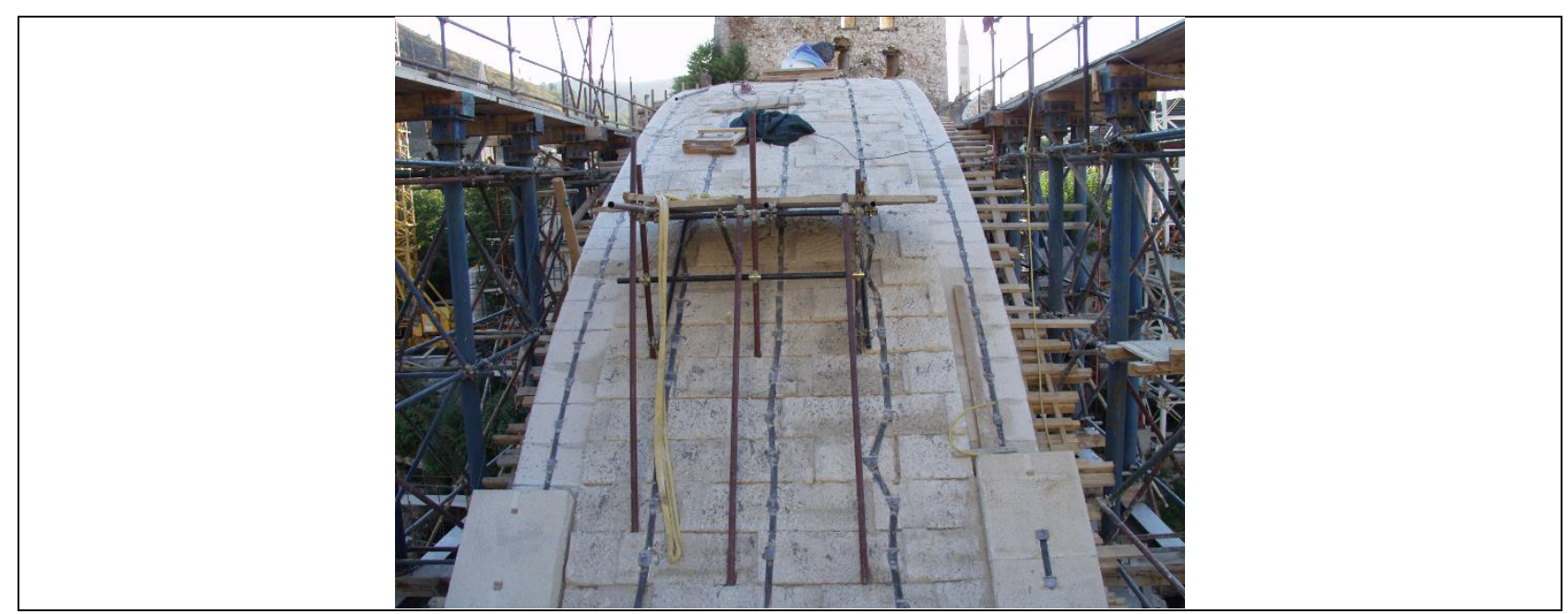

Fig. 16. The last rows of stone arch 


\section{Conclusion}

This is just a short overview of the building, restoration works, historical and archaeological research and reconstruction of the Old Bridge. There is no mention here of the works performed after the arch was finished (insulation works, setting of paving, stone and steel fencing), which were also very serious because a single detail might have spoiled all previously exerted efforts. A comprehensive analysis of the project (lit. (3)) and seemingly unimportant parts of the building and reconstruction process, which are presently insufficiently known and covered, shall be presented in a more detailed manner with an appropriate historic and professional detachment.

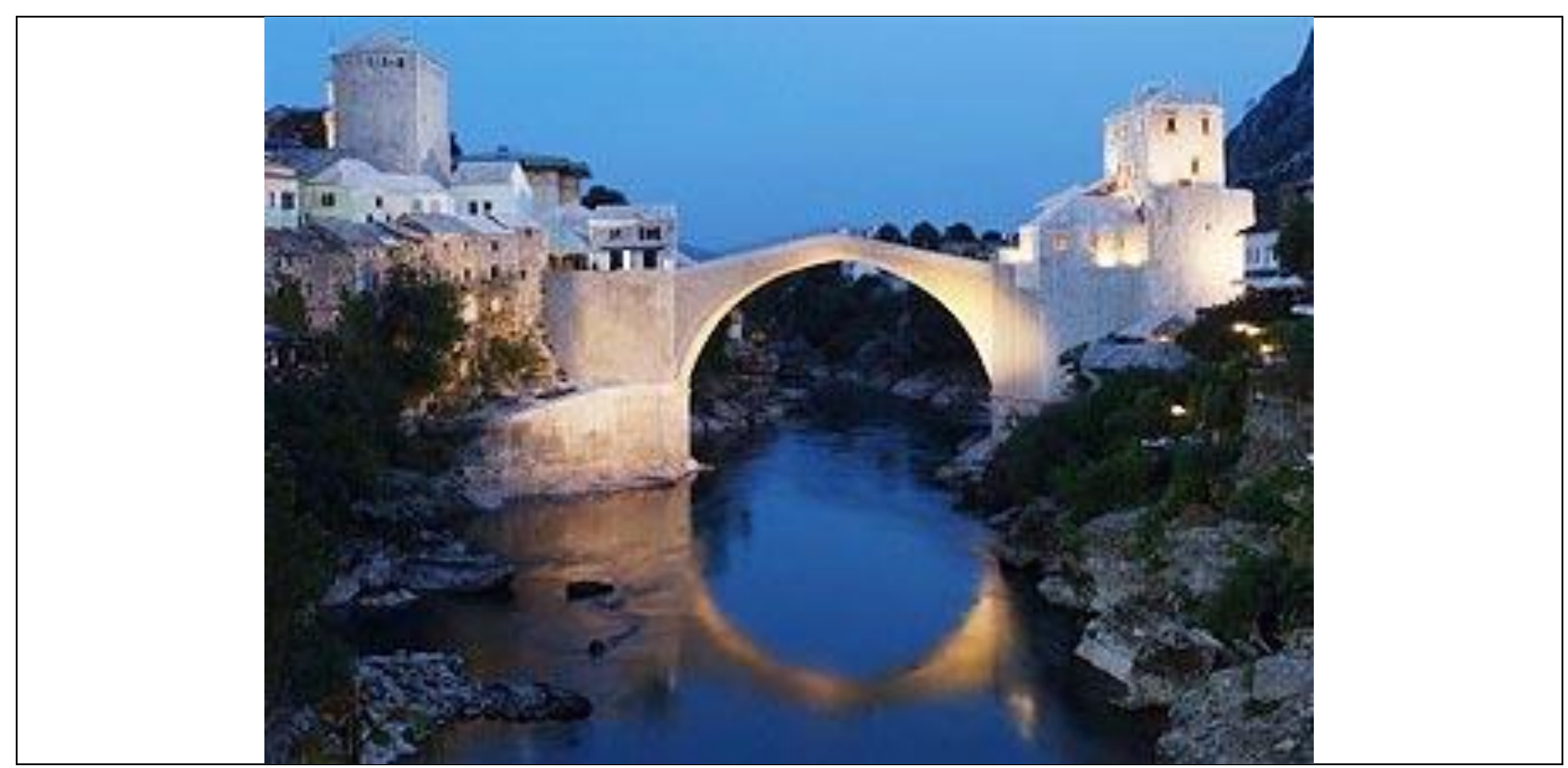

Fig. 17. A "new" Old Bridge

\section{References}

UNESCO, PCU. (2004). A Bridge Story, MOSTart, World Bank, Project Coordination Unit City of Mostar, Mostar,

Colak, I. (2003). The Reconstruction of the Old Bridge of Mostar, BKZ, Hochbauamt, Baubereich 1, Schweizerischer Werkbund, Zuerich,

Gotovac, B. (2004). Reconstruction of the Old Bridge, Ceste $i$ mostovi, Journal of the Croatian Road Transport Association, no. 7-9, Zagreb

Krsmanovic, D., Dolarovic, H., Langof, Z. (1967). Restoration of the Old Bridge in Mostar, Excerpt from the annual Naša starina XI, Sarajevo

Milosevic, A., Kovacevic, N. (2004). Archaeological research into Mostar fortification in 2002 and 2003, annual Herzegovina, Mostar

Pekovic, Z. (2002). Soil investigation of Mostar bridge fortifications, Proceedings 2, Faculty of Civil Engineering University of Mostar, Mostar 